\title{
Gazi Üniversitesi Tıp Fakültesi Öğrencilerinin Akılcı İlaç Kullanımına Yönelik Bilgi ve Davranışlarının Değerlendirilmesi
}

\author{
Evaluation of the Knowledge and Behaviors of Gazi University Medical Faculty \\ Students on Rational Use of Medicines
}

\section{Özgecan Gül Hızal' (i) Mehmet Alperen Özçelik² (i)}

\section{Mustafa Necmi ilhan ${ }^{2}$}

\footnotetext{
1 Sağlık Bakanlığı, Türkiye Illaç ve Tıbbi Cihaz Kurumu

${ }^{2}$ Gazi Üniversitesi Tıp Fakültesi, Halk Sağlı̆ı̆ Anabilim Dalı
}

Öz

Amaç: Bu çalışmada Gazi Üniversitesi Tıp Fakültesi öğrencilerinin mezuniyet öncesinde akılcı ilaç kullanımına yönelik bilgi ve davranışlarının değerlendirilmesi amaçlanmıştır.

Yöntem: Tanımlayıcı olarak planlanan araştırmanın evrenini Gazi Üniversitesi Tıp Fakültesi 1., 2., 3. ve 4. sınıf öğrencileri oluşturmaktadır. Çalışmaya toplamda 145 öğrenci katılmış olup sosyodemografik özellikler ve akılcı ilaç kullanım davranışlarına ilişkin 33 sorudan oluşan online anket uygulaması gerçekleştirilmiştir. Verilerin istatistiksel analizleri için SPSS-23 paket programı kullanılmıştır. Tanımlayıcı istatistikler kısmında kategorik değişkenler sayı, yüzde verilerek, sürekli değişkenler ise ortalama \pm standart sapma ve ortanca ile sunulmuştur. Kategorik değişkenlerin karşılaştırma analizlerinde Ki-kare testi kullanılmış, istatistiksel anlamlılık düzeyi $p<0,05$ olarak kabul edilmiştir.

Bulgular: Katılımcıların \%57,9'u kadın, \%42,1'i erkektir. Katılımcıların yaş ortalaması 20,99 olarak bulunmuştur. Kadınların \%65,4'ü, erkeklerin \%45,9'u gerekli olabileceği düşüncesiyle hasta olmadan ilaç kullanmaktadır. Kadınların \%66,7'si, erkeklerin ise \%49,2'si evinde hiç kullanılmamış veya yarım kalmış 6 veya daha fazla ilaç bulunmaktadır. Dönem 4 öğrencilerinin son kullanma tarihi geçtiği için kutusunu bile açmadan ilaçları atma eğilimi diğer dönemlerden anlamlı derecede yüksek bulunmuştur.

Sonuç: Öğrencilerin akılcı ilaç kullanım davranışları genel olarak yüksek bulunsa da soğuk zincir ilaçların doğru olmayan koşullarda saklanması, son kullanma tarihi geçtiği için atılan ilaç sayılarının yüksek olması, muayene olmadan ilaç kullanımı davranışlarının bulunması nedeniyle bazı konularda akılcı ilaç kullanımı ile ilgili eğitim ihtiyacı olduğunu göstermektedir.

Anahtar Kelimeler: Akılcı İlaç Kullanımı, Tıp Fakültesi, Tıp Eğitimi, Mezuniyet Öncesi Eğitim. 


\begin{abstract}
Objective: The aim of this study was to evaluate the knowledge and behavior of Gazi University Faculty of Medicine students regarding rational use of medicines before graduation.

Method: The population of the research, which was planned as a descriptive study, consists of 1st, 2nd, 3rd and 4th grade students of Gazi University Faculty of Medicine. A total of 145 students participated in the study, and an online questionnaire consisting of 33 questions on sociodemographic characteristics and rational drug use behaviors was conducted. SPSS-23 package program was used for statistical analysis of the data. In the descriptive statistics section, categorical variables were presented as numbers and percentages, and continuous variables were presented as mean \pm standard deviation and median. Chi-square test was used in the comparison analyzes of categorical variables, and the statistical significance level was accepted as $p<0.05$.
\end{abstract}

Results: $57.9 \%$ of the participants were female and $42.1 \%$ were male. The average age of the participants was found to be 20.99 years. $65.4 \%$ of women and $45.9 \%$ of men use medication without being ill, considering that it may be necessary. $66.7 \%$ of women and $49.2 \%$ of men have six or more unused or uncompleted medicines at home. Since the expiration date has passed, the tendency of the 4th grade students to throw away the drugs without even opening the box was found to be significantly higher than the others.

Conclusion: Although students' rational use of medicines behaviors are generally found to be high, it shows that there is a need for training on rational drug use in some subjects due to the fact that cold chain drugs are stored under incorrect conditions, the high number of drugs that are thrown away because of their expiration date is over and there are drug use behaviors without examination to physcian.

Keywords: Rational Use of Medicines, Faculty of Medicine, Medical Education, Pre-Graduation Education.

\section{GiRiş}

Dünya Sağlık Örgütü (DSÖ), akılcı ilaç kullanımını hastaya kendi klinik gereksinimlerine en uygun ilacın, uygun endikasyonda, uygun dozda/sürede ve maliyeti en düşük olanın verilmesi olarak tanımlamışır (1). Akılcı olmayan reçeteler hastalarda tedavide istenen etkinliğin sağlanmaması ve/veya toksisiteye neden olabilirken ekonomik yönden de önemli kayıplara yol açmaktadır. DSÖ'nün tahminlerine göre; ilaçların $\% 50$ 'sinden fazlası uygun olmayan şekilde reçetelenmekte, sağlanmakta veya satılmaktadır. Tüm hastaların yarısı da ilaçlarını doğru şekilde kullanamamaktadır (2). Akılcı olmayan ilaç kullanımının sosyokültürel, ekonomik, yönetsel ve düzenleyici mekanizmalardan kaynaklanan birçok nedeni bulunmakla birlikte hekimlerin bu konudaki bilgi, tutum ve davranışlarındaki eksiklikleri de akılcı olmayan reçeteleme ve ilaç kullanımına neden olmaktadır (3-5).

DSÖ ülkelere AiK'in teşvik edilmesi için 12 temel düzeltici faaliyet önermektedir. Bu faaliyetler arasında "mezuniyet öncesi müfredatta probleme dayalı farmakoterapi eğitimi verilmesi" ve "hizmet içi sürekli tıp eğitimleri düzenlenmesi" başlıkları yer almaktadır (2). Ülkemizde ve dünyada yapılan çalışmalar akılcı ilaç kullanımına yönelik eğitimlerin mezuniyet öncesi dönemde verilmesini tavsiye etmektedir (6). Serah Johny ve arkadaşları tarafından 150 tıp fakültesi öğrencisi ile ilaç kullanım alışkanlıkları üzerine yapılan bir çalışmada öğrencilerin \%91,3'ünün kendi kendilerine ilaç kullandıkları ve bu durumun basit rahatsızlıklarda zaman kazandırdığı sonucuna ulaşıımıştır. Ürtiker, baş ağrısı ve yüksek ateş için ilaç kullanan katılımcıların \%63,4'ü kullandıkları ilaçların yan etkisini bilmediklerini, \%8'i de bu ilaçlara bağlı reaksiyonlarla karşılaştıklarını belirtmiştir. Kullandıkları ilaçlara ilişkin bilgilerinin ise daha önceki reçetelerinden, ders kitaplarından, büyüklerinden ve arkadaşlarından olduğu sonucu görülmektedir. Çalışmada tıp eğitimi sırasında akııı ilaç kullanımına ilişkin eğitimlerin artıııması gerektiği sonucu vurgulanmıştır (7).

Ülkemizde de akılcı ilaç kullanımı çalışmaları uzun yıllardır devam etmekte olup hekim, eczacı, yardımcı sağlık personeli, halk ve ilaç endüstrisine yönelik akılcı ilaç kullanımı konusunda farkındalık, bilgi ve bilinç düzeylerini artırmak amacıyla Türkiye İlaç ve Tıbbi Cihaz Kurumu tarafından "Akılcı İlaç Kullanımı Ulusal Eylem Planı 20142017" hazırlanmıştır. Bu eylem planında ilaçların akılcı kullanımı ve kanıta dayalı tıp uygulamaları hakkında hekimler için bilgilendirme materyallerinin oluşturulması; Tıp ve Diş Hekimliği Fakültelerinin eğitim müfredatlarına konu ile ilgili ders ve staj programlarının eklenmesinin sağlanması ve asistan hekimlerin uzmanlık eğitim müfredatına akılcı ilaç kullanımının eklenmesi faaliyetleri öne çıkmaktadır (8). 
Bu çalışmada Gazi Üniversitesi Tıp Fakültesi öğrencilerinin mezuniyet öncesinde akılcı ilaç kullanımına yönelik bilgi ve davranışları değerlendirilmesi amaçlanmıştır.

\section{YÖNTEM}

\section{Veri Toplama Aracı}

Konu ile ilgili güncel literatürler incelenmiş, Türkiye İlaç ve Tıbbi Cihaz Kurumu Akılcı İlaç Kullanımı Dairesi tarafından hazırlanan akılcı ilaç kullanımı anketinde yapılan düzenlemeler ve değişiklikler sonrasında veri toplama aracı olarak kullanılmıştır. $\mathrm{Bu}$ anket formu; sosyodemografik özellikler (yaş, cinsiyet, dönem) ve akılcı ilaç kullanım davranışlarına ilişkin 33 sorudan oluşmaktadır.

\section{Verilerin Toplanması}

Araştırmanın evrenini Gazi Üniversitesi Tıp Fakültesi 1., 2., 3. ve 4. sınıf öğrencileri oluşturmaktadır. Toplam 1.250 öğrenci evren alınarak \%95 güven aralığı, \%5 standart sapma ve akılcı ilaç kullanım sıklı̆ı̆ \%50 (bilinmeyen sıklık) baz alınarak örneklem büyüklüğü 384 öğrenci olarak hesaplanmıştır. Ulaşamama, cevap vermeme gibi faktörler göz önünde bulundurularak \%10 fazlası yedek olarak belirlenmiş olup 484 öğrenci sınıf sayısına göre ağırlıklandırılarak seçilmiştir. Veriler araştırmacı tarafından 22.06.2021-10.09.2021 tarihleri arasında online olarak toplanmıştır. Çalışmaya toplamda 145 öğrenci katılmıştır.

\section{Verilerin Analizi}

Verilerin istatistiksel analizleri için Statistical Package for Social Sciences (SPSS), sürüm 23.0 (SPSS Inc. Chicago, USA) bilgisayar paket programı kullanılmıştır. Tanımlayıcı istatistikler kısmında kategorik değişkenler sayı, yüzde ile sürekli değişkenler ise ortalama \pm standart sapma ve ortanca (en küçük- en büyük değer) ile sunulmuştur. Kategorik değişkenlerin karşılaştırma analizlerinde Ki-kare testi kullanılmış, istatistiksel anlamlılık düzeyi $p<0,05$ olarak kabul edilmiştir.

\section{BULGULAR}

Tablo 1. Katılımcıların Bazı Demografik Özellikleri, Ankara, 2021

\begin{tabular}{|l|c|c|}
\hline \multicolumn{2}{|l|}{ Sayı } & $\%{ }^{*}$ \\
\hline Cinsiyet (n=145) & 84 & 57,9 \\
\hline Erkek & 61 & 42,1 \\
\hline Kadın & 24 & 16,6 \\
\hline Dönemi & 27 & 18,6 \\
\hline 1 & 37 & 25,5 \\
\hline 2 & 57 & 39,3 \\
\hline 3 & 76 & 52,4 \\
\hline 4 & 30 & 20,7 \\
\hline İkamet yeri & 39 & 26,9 \\
\hline Aile Yanı & 23 & 15,9 \\
\hline Yurt & 122 & 84,1 \\
\hline Öğrenci Evi & 24 & 16,6 \\
\hline Tanı Koyulmuş Herhangi Bir Kronik Hastalık \\
\hline Var & 21 & 83,4 \\
\hline Yok & \multicolumn{2}{|c|}{} \\
\hline Düzenli olarak kullanılan ilaç & \\
\hline Var & 24 \\
\hline Yok & 121 \\
\hline
\end{tabular}

*Yüzde

Ankete katılan öğrencilere ait demografik veriler Tablo 1'de verilmiştir. Katılımcıların \%57,9'ü kadın, \%42,1'i erkektir. Katılımcıların yaş ortalaması $20,99 \pm 1,96$ ve yaş ortancası 21 'dir (min:18, max:32). Katılımcıların \%16,6'sı 1. sınıf, $\% 18,6$ 'sı 2. sınıf, \%25,5'i 3. sinıf ve \%39,3'ü ise 4. sinıftır. Katıııcıların \%52,4'ü aile yanında, \%26,9'u öğrenci evinde, \%20,7'si ise yurtta kalmaktadır. Katılımcıların \%15,9'unun tanı konulmuş bir kronik hastalığı bulunmakta olup \%16,6'sı düzenli olarak ilaç kullanmaktadır.

Tablo 2. Öğrencilerin Dönemine Göre Son Kullanma Tarihi Geçtiği İçin Kutusu Bile Açılmadan İlaç Atılma Durumu, Ankara, 2021

\begin{tabular}{|l|c|c|c|c|}
\hline \multirow{2}{*}{} & \multicolumn{4}{|c|}{$\begin{array}{c}\text { Son Kullanma Tarihi Geçtiği için Kutusu Bile } \\
\text { Açılmadan Ilaç Atılma Durumu }\end{array}$} \\
\cline { 2 - 5 } & \multicolumn{3}{|c|}{ Atılıyor } & \multicolumn{2}{c|}{ Atılmıyor } \\
\cline { 2 - 5 } & Sayı & $\% *$ & Sayı & $\% *$ \\
\hline Öğrencilerin Kaçıncı Dönem Olduğu (n=145) \\
\hline Dönem 1 & 18 & 25,0 & 6 & 75,0 \\
\hline Dönem 2 & 13 & 51,8 & 14 & 48,2 \\
\hline Dönem 3 & 22 & 40,5 & 15 & 59,5 \\
\hline Dönem 4 & 19 & 66,7 & 38 & 33,3 \\
\hline \multicolumn{5}{|c|}{$\mathbf{X}^{2}=\mathbf{1 4 , 0 9 8}$} \\
\hline
\end{tabular}

*Satır yüzdesi 
Katılımcılara evlerinde hiç kullanılmamış/yarım kalmış ilaç sayısı sorulmuş olup \%2,8'i hiç olmadığını, \%37,9'u 1-5 arasında, \%29,0'u 6-10 arasında olduğunu, \%30,3'u ise bu sayının 10'un üzerinde olduğunu belirtmiştir. Tablo 2'de öğrencilerin dönemine göre son kullanma tarihi geçtiği için kutusu bile açılmadan ilaç atılma durumu sunulmuştur. Dönem 1 öğrencilerinin \%25,0'ı, dönem 2 öğrencilerinin \%51,8'i, dönem 3 öğrencilerinin \%40,5'i, dönem 4 öğrencilerinin ise \%66,7'si son kullanma tarihi geçtiği için kutusunu bile açmadan ilaçların atıldığını ifade etmiştir. Öğrencilerin okudukları döneme göre ilaç atma durumları arasındaki fark istatistiksel olarak anlamlı bulunmuştur $(p=0,003)$. Bunun nedeninin öğrencilerin dönemi ilerledikçe aldıkları eğitimler ile farmakoloji bilgilerinin ve son kullanma tarihinin önemi ile ilgili farkındalığının artmış olabileceği düşünülmektedir.

Tablo 3. Öğrencilerin Cinsiyetlerine Göre Akılcı İlaç Kullanımının Değerlendirilmesi, Ankara, 2021

\begin{tabular}{|c|c|c|c|c|}
\hline & \multicolumn{4}{|c|}{ Cinsiyet } \\
\hline & \multicolumn{2}{|c|}{ Kadın } & \multicolumn{2}{|c|}{ Erkek } \\
\hline & Sayı & $\% *$ & Sayı & $\% *$ \\
\hline \multicolumn{5}{|c|}{$\begin{array}{l}\text { Gerekli Olabileceği Düşüncesiyle Hasta Olmadan İlaç } \\
\text { Kullanma Durumu }(n=145)\end{array}$} \\
\hline Evet & 55 & 65,4 & 28 & 45,9 \\
\hline Hayır & 29 & 34,6 & 33 & 54,1 \\
\hline \multicolumn{5}{|c|}{$x^{2}=5,532$} \\
\hline \multicolumn{5}{|c|}{$\begin{array}{l}\text { Soğuk Zincir İlaçlarının Buzdolabında Hangi Bölümde } \\
\text { Saklandığı }(n=145)\end{array}$} \\
\hline $\begin{array}{l}\text { Buzdolabının } \\
\text { Kapağında }\end{array}$ & 70 & 83,3 & 35 & 57,3 \\
\hline $\begin{array}{l}\text { Buzdolabının } \\
\text { rafında veya } \\
\text { Buzlukta }\end{array}$ & 14 & 16,7 & 26 & 42,7 \\
\hline \multicolumn{5}{|c|}{$x 2=10,654$} \\
\hline \multicolumn{5}{|c|}{$\begin{array}{l}\text { Evde Hiç Kullanımamış veya Yarım Kalmış Kaç Kutu i̇laç } \\
\text { Bulunduğu (n=145) }\end{array}$} \\
\hline $\begin{array}{l}5 \text { veya Daha } \\
\text { Az }\end{array}$ & 28 & 33,3 & 31 & 50,8 \\
\hline $\begin{array}{l}6 \text { veya Daha } \\
\text { Fazla }\end{array}$ & 56 & 66,7 & 30 & 49,2 \\
\hline 4,477 & $p=0,034$ & & & x $2=$ \\
\hline
\end{tabular}

*Sütun Yüzdesi
Tablo 3'te öğrencilerin cinsiyetlerine göre akılcı ilaç kullanımının karşılaştırılması sunulmuştur. Kadınların \%65,4'ü, erkeklerin \%45,9'u gerekli olabileceği düşüncesiyle hasta olmadan ilaç kullanmaktadır. Bu grup ilaçlar arasında en çok ağrı kesiciler $(\% 59,3)$, merhemler $(\% 26,9)$, soğuk algınlığı ilaçları $(\% 24,8)$ ve vitaminler $(\% 23,4)$ yer almaktadır. Cinsiyetler arası gerekli olabileceği düşüncesiyle hasta olmadan ilaç kullanımı arasında istatistiksel olarak anlamlı bir fark saptanmıştır $(p=0,019)$. Soğuk zincir ilaçların saklandığı bölüme bakıldığında kadınların \%83,3'ü, erkeklerin \%57,3'ü buzdolabı kapağında saklamaktadır. Cinsiyetler arası saklama şekli arasındaki fark istatistiksel olarak anlamlı bulunmuştur $(p=0,001)$. Kadınların $\% 66,7$ 'sinin, erkeklerin ise \%49,2'sinin evinde hiç kullanılmamış veya yarım kalmış 6 veya daha fazla ilaç bulunmaktadır. Cinsiyetler arası evde bulunan ilaç kutu sayısı arasındaki fark istatistiksel olarak anlamlıdır $(p=0,034)$. Buna göre kadınlarda akılcı ilaç kullanım uygulamalarında belirgin şekilde yanlış uygulama görülmektedir.

Katılımcıların \%82,8'i bir tedavi sonrası artan ilaçlarını gerektiği zaman kullanmak üzere sakladığını ifade etmiştir. Tekrar kullanmak istediğinde \%49,0'u hekime, \%9'u eczacıya danıştığını belirtirken \%.27,6'sı daha önce kullandığı için kimseden bilgi almadığı cevabını vermiştir. Evde bulundurulan ilaçları tekrar kullanırken dikkat edilen hususlara birden fazla cevap verilmiş olup verilen cevaplar arasında en çok hastalığa uygun olması $(\% 93,8)$ ve son kullanma tarihinin geçmemiş olması $(\% 90,3)$ yer almaktadır (Şekil 1). 
Şekil 1. Katıımcıların Evde Bulunan İlaçları Tekrar Kullanırken Dikkat Ettikleri Hususlar, Ankara, 2021

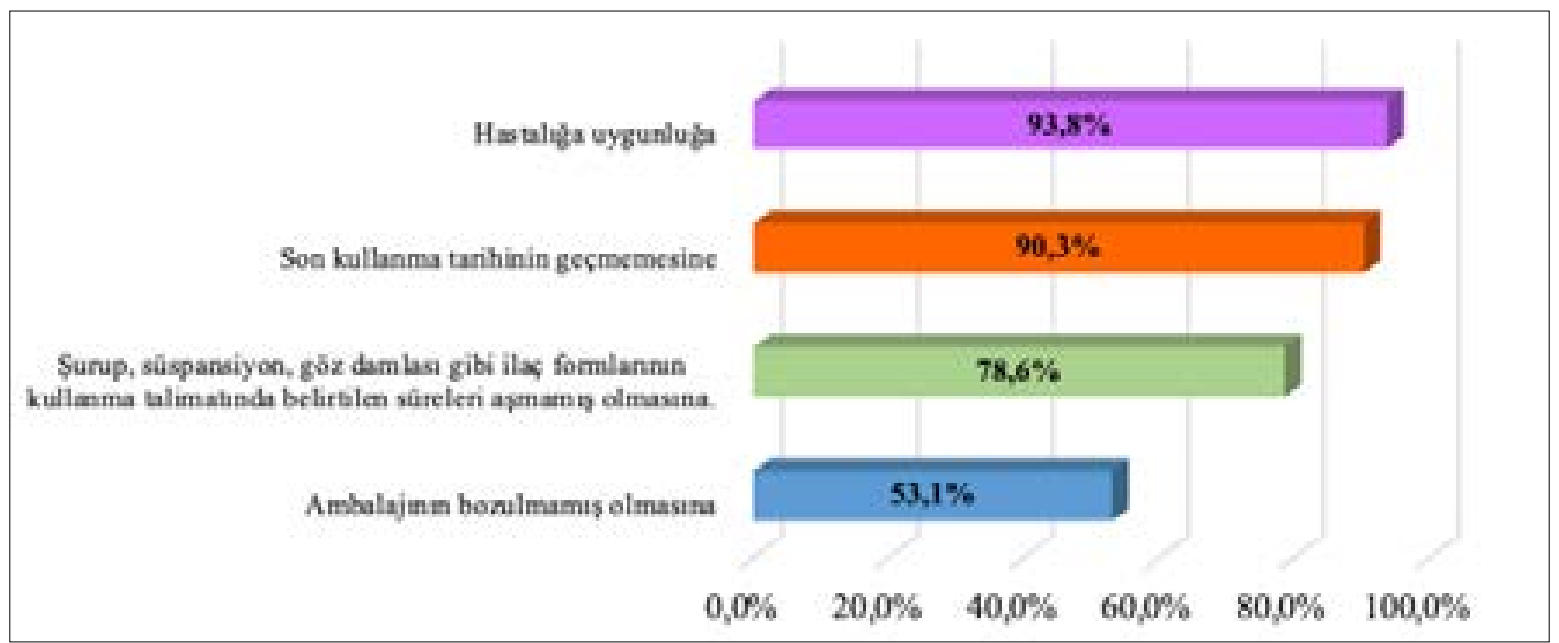

Katılımcıların \%21,4'ü üzerinde saklama koşulları ile ilgili herhangi bir uyarı bulunmayan ilaçları buzdolabında, \%78,6'ı oda sıcaklığında, serin ve kuru bir yerde sakladığını belirtmiştir. Soğuk zincir ilaçları ise \%72,4'ü buzdolabının kapağında, \%27,6'sı buzdolabının rafında ya da buzlukta/ derin dondurucuda sakladığını belirtmiştir. Buna göre katııımcıların soğuk zincir ilaçların saklanma koşulları ile ilgili bilgi eksikliği olduğu tespit edilmiştir.

Katılımcıların \%94,5'i ilacı hekimin önerdiği saatte kullandığını, \%97,2'si hekime danışmadan ilaç dozunu değiştirmediğini belirtmiştir. Katılımcıların yalnızca \%4,8'i grip, nezle, soğuk algınlı̆̆ gibi şikâyetleriniz üzerine muayene olmadan kendi başına antibiyotik kullandığını, $\% 9,7$ 'si antibiyotiğe başladığını ancak kendini iyi hissettiğinde ilaç kullanmayı bıraktığını belirtirken büyük çoğunluğu $(\% 85,5)$ muayene olmadan antibiyotik kullanmadığını belirtmiştir.

Katılımcıların \%56,6'sı hekime muayene olmadan eczaneden ilaç aldıklarını belirtmiştir. Herhangi bir ilaç ile ilgili bilgi almak için başvurulan bilgi kaynakları sorusuna katılımcılar birden fazla yanıt vermiş olup en sık internet $(\% 75,2)$, sağlık profesyoneli $(\% 44,1)$, tanı ve tedavi kılavuzları $(\% 43,4)$, ders notları $(\% 41,4)$ ve meslektaşları $(\% 40,7)$ yer almaktadır (Şekil 2). illk sırada yer alan internet cevabının PubMed, Clinical Key ve buna benzer güvenilir bilgi kaynaklarından sağlanıp sağlanmadığı ile ilgili bir soru yer almadığından tam olarak tespit edilememiştir.

Şekil 2. Katılımcıların Başvurduğu İlaç Bilgi Kaynakları, Ankara, 2021

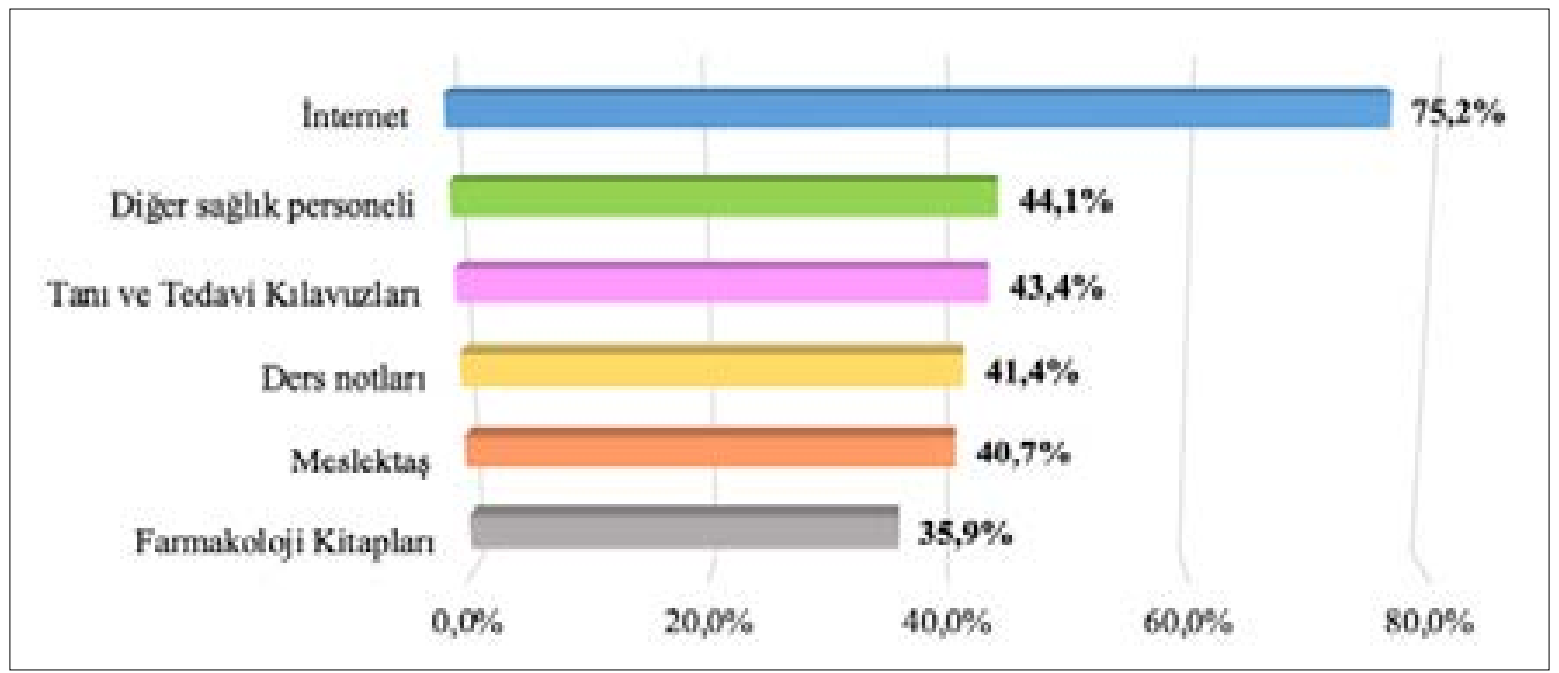


Anket uygulaması COVID-19 pandemisi sürecinde gerçekleştirildiği için COVID-19'a ilişkin sorulara da yer verilmiştir. Buna göre katılımcıların \%36,6'sının kendisi veya ailesinin COVID-19 tanısı aldığı, tanı alanların $\% 71,7$ 'sinin tedavi için verilen ilaçları kullandığı ve \%37,7'sinin COVID-19 tedavi süresince hekimin önerisi dışında ilaç/gıda takviyesi/bitkisel preparat kullandığı bilgisine ulaşılmıştır. Katılımcıların \%51,7'si pandeminin başlangıcından itibaren hekim önerisi dışında ilaç kullandığını ifadeetmiştir. Bu ilaçlarçoğunluklaağrıkesiciler, vitaminler ve soğuk algınlığı ilaçları olup kullanma nedeni olarak en sık doktora gitmeye gerek duymama $(\% 22,8)$ ve pandemi sebebiyle sağlık merkezine başvurmaktan çekinme $(\% 22,1)$ yer almaktadır. Katılımcıların \%82,1'inin daha önce akılcı ilaç kullanımı konusunda eğitim almadığı belirlenmiş olup \%84,1'i akılcı ilaç kullanımı konusunda eğitim almak istediğini belirtmiştir.

\section{TARTIŞMA ve SONUÇ}

19 Mayıs Üniversitesi Tıp Fakültesi öğrencilerinin antibiyotik kullanma durumlarının değerlendirilmesi amacı ile 2018 yılında bir çalışma gerçekleştirilmiştir. 640 öğrencinin katılı̆̆ı bu çalışmada öğrencilerin \%17,5'i kronik bir hastalığı bulunduğunu, \%80,3'ü doktor reçetesi ile antibiyotik kullandığını, \%34,6'sı ilacı bitene kadar, \%38,7'si şikayetleri azalıncaya kadar kullandığını ve \%26,2'si hekimin önerdiği sürede antibiyotik kullandığını bildirmiş ve çalışma sonucunda antibiyotik kullanma konusundaki farkındalıklarını artırmak gerektiği sonucuna ulaşılmıştır. Bizim çalışmamızda katılımcıların \%85,5'i hekim muayenesi dışında antibiyotik kullanmadığını, \%79,3'ü verilen ilaçları önerilen şekilde, \%97,2'si önerilen saatte kullandığını ifade etmiş ve bu sonuçlar açısından çalışmamız ile benzerlik göstermektedir (9).

2013 yılında M. Necmi İlhan ve arkadaşları tarafından yürütülen çalışmada Ankara il merkezinde üç ilçedeki bazı aile sağlığı merkezlerine başvuran 18 yaş üstü kişilerin ilaç kullanım özellikleri değerlendirilmiştir. 1.990 kişinin katıldığı bu çalışmada katılımcıların yaklaşık yarısının $(\% 40,5)$ herhangi bir sağlık sorunu olduğunda sağlık kuruluşuna başvurmadığı, azımsanamayacak bir kısmının ise evdeki ilaçları kullanma $(\% 30,2)$ ve bitkisel/geleneksel yöntem kullanma $(\% 20,8)$ gibi yollara başvurduğu saptanmıştır. Bizim çalışmamızın örnekleminde Tıp Fakültesi öğrencileri yer aldığından akılcı ilaç kullanımına yönelik bilgi ve farkındalık daha yüksek bulunmuştur (10).

Mersin Üniversitesi Tıp Fakültesi'nde yapılan bir çalışmada akılcı ilaç kullanımı eğitimi alan dönem 6 öğrencilerinin eğitim ile ilgili görüşleri değerlendirilmiştir. 118 öğrencinin dâhil edildiği anket çalışmasında öğrencilerin \%83,0'ı akılcı ilaç kullanımına yönelik aldıkları stajı verimli bulmuş, öğrencilerin tamamı kişisel ilaç seçimi ve kazanılması gereken becerileri ilk kez bu eğitimde öğrendiklerini belirtmiştir. Öğrencilerin \%97,4'ü stajdaki eğitimin kanıta dayalı ilaç seçimi ve reçete yazma konusunda farkındalık oluşturduğunu, \%90,7'si da yapılan bu uygulamaların hekimlik pratiklerinde faydası olacağını ifade etmiştir (11). Bizim çalışmamızda öğrencilerin büyük çoğunluğu klinik öncesi dönemde olduğundan $\% 82,1$ 'i henüz akılcı ilaç kullanımı eğitimi almamış olup \%84,1'i akılcı ilaç kullanımı ile ilgili eğitim almak istediğini belirtmiştir.

Marmara Üniversitesi Tıp Fakültesi'nde klinik öncesi dönem öğrencilerinin akılcı ilaç kullanımına yönelik bilgi, görüş ve davranışlarının saptanması amacıyla 1, 2 ve 3. sınıf öğrencileri ile bir çalışma yapılmış ve çalışmaya 412 öğrenci dahil edilmiştir. Katılımcıların \%64,7'si tıp fakültesinde akılcı ilaç kullanımından yeterince bahsedilmediğini, \%65,5'i akılcı ilaç kullanımı eğitiminin klinik öncesinde 1. sınıftan itibaren verilmeye başlanması gerektiğini belirtmiştir. Katılımcıların \%74,4'ü tıp fakültesi eğitiminin akılcı ilaç kullanımı ile ilgili davranış ve tutumlarda olumlu yönde değişim yarattığını ifade etmiştir (12).

Ülkemizde akılcı ilaç kullanımı çalışmaları uzun yıllardır devam etmekte olup birçok tıp fakültesinin müfredatında konu ile ilgili ders ve staj programları yer almaktadır. Tıp fakültesi sırasında başlayan eğitim müdahalelerinin hekimlerin farkındalığını arttırarak kariyerin ileri döneminde yapılan eğitimlere kıyasla daha etkin ve verimli olduğu bilinmektedir (13). Çalışmamız sonucunda elde edilen verilere göre öğrencilerin akılcı ilaç kullanım davranışları genel olarak yüksek bulunsa da soğuk zincir ilaçların doğru olmayan koşullarda saklanması, son kullanma tarihi geçtiği için atılan ilaç sayılarının yüksek olması, muayene olmadan ilaç kullanımı davranışlarının bulunması nedeniyle bazı konularda akılcı ilaç kullanımı ile ilgili eğitim ihtiyacı olduğunu göstermektedir.

Etik Komite Onayı: Bu çalışma için 20.04.2021 tarihinde Gazi Üniversitesi Etik Komisyonu'ndan etik komite onayı alınmıştır.

Hasta Onamı: Hasta onamı bu çalışmaya katılan katılımcılardan alınmıştır.

ÇıkarÇatışması: Yazarlarçıkarçatışması bildirmemişlerdir.

Finansal Destek: Yazarlar bu çalışma için finansal destek almadıklarını beyan etmişlerdir. 


\section{KAYNAKLAR / REFERENCES}

1. De Vries TPGM, Henning RH, Hogerzeil HV, Fresle DA. Guide to Good Prescribing. WHO Action Programme on Essential Drugs. World Health Organization, Geneva 1994. https://apps.who.int/ iris/handle/10665/59001

2. World Health Organization (2002). Promoting Rational use of Medicines: Core Components WHO Policy Perspectives on Medicines. Report WHO/EDM/2002.3. Geneva https://apps.who.int/iris/handle/10665/67438

3. World Health Organization. Action Programme on Essential Drugs and Vaccines. (1993). How to Investigate Drug Use in Health Facilities: Selected Drug Use İndicators. World Health Organization. https://apps.who.int/iris/handle/10665/60519

4. World Health Organization. (2001). Teacher's Guide to Good Prescribing Hans V. Hogerzeil (editor) ... [et al.]. World Health Organization. https://apps.who.int/iris/handle/10665/67010

5. le Grand A, Hogerzeil HV, Haaijer-Ruskamp FM. Intervention Research in Rational Use of Drugs: A Review. Health Policy Plan. 1999;14(2):89-102. doi:10.1093/heapol/14.2.89

6. Akıcı A., Gelal A., Erenmemişoğlu A. Akılcı Illaç Kullanımı Eğitimi Uygulama Sürecinde Türkiye'deki Tıp Fakültelerinde Farmakoloji Anabilim Dallarının Durumunun İncelenmesi. Tıp Eğitimi Dünyası. 2011; 29(29): 11-20.

7. Johny, S., Torgal, S., Mathew, A. (2017). Assessment of Knowledge, Attitude and Practice of Self- medication among Second Year MBBS Students", Indian Journal of Pharmacy and Pharmacology. 4. 42-44. DOI: 10.18231/2393-9087.2017.0011

8. Türkiye Akılcı İlaç Kullanımı E-Bülteni Cilt:2 Sayı:9, Eylül 2015. http://www.akilciilac.gov.tr/wp-content/uploads/2015/09/aikbltn-12-i.pdf.

9. Kukula O. Tıp Fakültesi Öğrencilerinin Antibiyotik Kullanımının Değerlendirilmesi. Ortadoğu Tıp Dergisi 2019; 11(3): 239-243. https://doi.org/10.21601/ortadogutipdergisi.482584

10. İlhan M., Aydemir Ö., Çakır M., Aycan S. (2014). Akılcı olmayan İlaç Kullanım Davranıșları: Ankara'da Üç İlçe Örneği, Turkish Journal of Public Health, 12 (3) , 188-200. DOI: 10.20518/ thsd.91650

11. Tiftik, R. N., Kıroğlu, O., Berktaş, F., Ün, İ., Karataş, Y. (2021). Mersin Üniversitesi Hastanesi'nde Çalışan Araştırma Görevlilerinin Akılcı İlaç Kullanımı Konusunda Bilgi ve Yaklaşımları. Mersin Üniversitesi Sağlık Bilimleri Dergisi, 14 (1), 65-76. DOI: 10.26559/mersinsbd.872260

12. Güngör BB. ve ark. Marmara Üniversitesi Tıp Fakültesi Klinik Öncesi Dönem Öğrencilerinin Akılcı İlaç Kullanımına Yönelik Bilgi, Görüş ve Davranışları. The Journal of Turkish Family Physician 2020; 11(2): 68-82. DOI: 10.15511/tttfp.20.00268.)

13. Ross S., Bond C., Rothnie H., Thomas S., Macleod M J. What is the scale of prescribing errors committed by junior doctors? A systematic review. British Journal of Clinical Pharmacology 2009;67(6):629-640. doi:10.1111/j.1365-2125.2008.03330.x 